\title{
КАЧЕСТВЕННЫЙ И КОЛИЧЕСТВЕННЫЙ СОСТАВ МИКРОБИОТЫ УРОГЕНИТАЛЬНОГО ТРАКТА ПРИ ИНФИЦИРОВАННОМ ВЫКИДЫШЕ
}

\section{QUALITATIVE AND QUANTITATIVE COMPOSITION OF THE UROGENITAL TRACT MICROBIOTA IN INFECTED MISCARRIAGE}

\section{N. Ruhlyada \\ S. Vinnikova \\ L. Tsechoyeva}

Summary. An infected miscarriage is an interruption of a developing pregnancy, which is characterized by the presence of fever, chills, malaise, lower abdominal pain, blood, sometimes pus-like discharge from the genital tract. This pathology can lead to a violation or loss of reproductive function. In the North-Western district in 2012-2013, 14.3\% died from termination of pregnancy before 22 weeks, $16 \%$ died from septic complications, and $3.7-5.9 \%$ died from miscarriage initiated in an outof-hospital facility. The aim of this work is to study the qualitative and quantitative composition of the urogenital tract microbiota in infected miscarriage using highly informative molecular genetic methods. The study was conducted on the basis of the SP research Institute. Janelidze in women of reproductive age. The main clinical form of infectious miscarriage is endometritis in 88 (63.8\%). The study found that absolute pathogens, namely Chlamydia trachomatis, Mycoplasma genitalium, Neisseria gonorrhoeae, were detected in 36 (26.1\%). When examining the vaginal discharge using the "Femoflor 16" method, Gardnerella vaginalis $38 \%$ and Atopobium vaginae $36 \%$ were found. The content of one or more facultative (family Enterobacteriacea, Streptococcus spp., Staphylococcus spp.) and/or obligate anaerobes (Gardnerella vaginalis, Atopobium vaginae) in a significant titer (>105 CFU) was detected in 54\% and $28 \%$. When comparing the results of the study with data from the last five years, there is a tendency to increase the number of opportunistic flora (Gardnerella vaginalis, atopobium vaginae Streptococcus spp., Staphylococcus spp. and others), an increase in the combination of Mycoplasma hominis and Ureaplasma species (5.8\%), while reducing the frequency of detection of STI pathogens (Chlamydia trachomatis) or a combination of infections associated with STIs (Chlamydia trachomatis, Neisseria gonorrhoeae and Mycoplasma genitalium). Verification of the microbiota allows applying a differentiated approach to prescribing antibacterial therapy before starting treatment, and if necessary, making an adequate change to antimicrobial therapy if it is ineffective.

Keywords: Infected miscarriage, microbiota, urogenital tract, antimicrobial therapy, "Femoflor 16".
Рухляда Николай Николаевич

Д.м.н., профессор, ФГБОУ ВО «Санкт-Петербургский государственный педиатрический медичинский университет» Минздрава России Винникова Симона Викторовна Аспирант, ФГБОУ ВО «Санкт-Петербургский государственный педиатрический медицинский университет» Минздрава России simona.vinnikova@yandex.ru

Цечоева Лейла Шахмурзаевна

К.м.н., ассистент, ФГБОУВО «Санкт-Петербургский государственный педиатрический медицинский университет» Минздрава России

Аннотация. Инфицированный выкидыш — это прерывание развивающейся беременности, которое характеризуется наличием лихорадки, озноба, недомогании, болями внизу живота, кровяными, иногда гноевидными выделениями из половых путей. Данная патология способна привести к нарушению или утрате репродуктивной функции. В Северо-Западном округе за 2012-2013 гг. от прерывания беременности до 22 недель умерло 14,3\%, от септических осложнений 16\%, от выкидыша, начатого внебольничном учреждении, умерло 3,7-5,9\%. Целью работы является изучение качественного и количественного состава микробиоты урогенитального тракта при инфицированном выкидыше с помощью высокоинформативных молекулярно-генетических методов. Исследование проводилось на базе НИИ СП им. Джанелидзе у женщин репродуктивного возраста. Основной клинической формой инфекционного выкидыша является эндометрит у 88 (63,8\%). В результате исследования установлено, что абсолютные патогенны, а именно Chlamydia trachomatis, Mycoplasma genitalium, Neisseria gonorrhoeae, были выявлены у 36 (26,1\%). При исследовании отделяемого из влагалища методом «Фемофлор 16» были обнаружены Gardnerella vaginalis $38 \%$ и Atopobium vaginae $36 \%$. Содержание одного или нескольких факультативных (семейство Enterobacteriacea, Streptococcus spp., Staphylococcus spp.) и/или облигатных анаэробов (Gardnerella vaginalis, Atopobium vaginae) В значительном титре (> 105 КОЕ) выявлены у $54 \%$ и 28\%. При сравнении результатов исследования с данными последних пяти лет, наблюдается тенденция увеличение количества условно-патогенной флоры (Gardnerella vaginalis, Atopobium vaginae Streptococcus spp., Staphylococcus spp. и др.), увеличение сочетания Mycoplasma hominis и Ureaplasma species (5,8\%), при одновременном снижении частоты выявления возбудителей ИППП (Chlamydia trachomatis) или сочетание инфекций ассоциированных с ИППП (Chlamydia trachomatis, Neisseria gonorrhoeae и Mycoplasma genitalium). Верификация микробиоты позволяет применить дифференцированный подход к назначению антибактериальной терапии до начала лечения, в случае необходимости произвести адекватную смену противомикробной терапии при ее неэффективности.

Ключевые слова: инфицированный выкидыш, микробиота, урогенитальный тракт, противомикробная терапия, «Фемофлор -16». 


\section{Ввемение}

и нфицированный выкидыш (код по МКБ О03.4) представляет собой прерывание развивающейся беременности, которое в последующем сопровождается развитием лихорадки, озноба, недомогании, болями внизу живота, кровяными, иногда гноевидными выделениями из половых путей. При физикальном обследовании выявляют тахикардию, тахипноэ, дефанс мышц передней брюшной стенки; при бимануальном исследовании - матка при пальпации болезненна и мягкой консистенции, а цервикальный канал шейки матки расширен [4].

На сегодняшний день септические осложнения занимают третье место в структуре материнской смертности и составляют около 11,1\% в России. В 2012-2013 гг. в Северо-Западном округе от прерывания беременности до 22 недель умерло 14,3\%, от септических осложнений $16 \%$. А от аборта, начатого во внебольничном учреждении, умерло 3,7-5,9\% [1,6,8,10,11].

Воспалительный процесс - причина невынашивания беременности, что ведет к структурным, функциональным изменениям шейки матки, в результате чего она становится восприимчива для инфекционных агентов. Происходит проникновение патогенных и/или условно-патогенных микроорганизмов, с последующим инфицированием плода, плаценты с плодными оболочками или эмбриона с хорионом [3,7,12].

Изучение качественного и количественного состава микробиоты урогенитального тракта является важной задачей на сегодняшний день, т.к. большая часть микроорганизмов, присутствующих во влагалище, могут стать причиной развития воспалительных заболеваний, которые в последующем приводит к инфицированному выкидышу $[2,10,11]$. Так микроорганизмы семейства Mycoplasma и Chlamydia занимают одно из ведущих мест среди возбудителей воспалительных заболеваний урогенитального тракта, их этиологическая роль в развитии неблагоприятных исходов беременности доказана [14, 17].

\section{Ше^ь}

Изучить качественный и количественный состав микробиоты урогенитального тракта при инфицированном выкидыше с помощью высокоинформативных молекулярно-генетических методов.

\section{Материалы и методы}

Проводилось ретроспективное исследование с октября 2017 по декабрь 2019 женщин $(\mathrm{n}=138)$ репро- дуктивного возраста (средний возраст $32 \pm 3,8$ лет), поступивших в НИИ скорой помощи им. И.И. Джанелидзе в гинекологическое отделение на стационарное лечение с диагнозом инфицированного выкидыша. Минимальный срок беременности у данной категории пациенток был 4 нед, а максимальный 20 нед (средний срок беременности 10,5 нед \pm 5 нед). При этом 95 (68,8\%) женщин состояли на учете в женской консультации, а 101 (73,2\%) были обследованы. До постановки данного диагноза 54 $(39,1 \%)$ пациентки принимали сохраняющую и поддерживающую терапию (дюфастон, утрожестан, поливитамины для беременных). Все пациентки после установления диагноза получали терапию антибактериальными препаратами широкого спектра действия (цефазолин, метрогил).

Диагноз инфицированный выкидыш у пациенток был установлен на основании наличия субфебрильной $\left(37,5{ }^{\circ} \mathrm{C}-37,9{ }^{\circ} \mathrm{C}\right)$ и фебрильной $\left(38,0{ }^{\circ} \mathrm{C}\right.$ и выше) лихорадки, тахикардии, тахипноэ, лейкоцитоза в крови, кровянистых и гноевидных выделений из половых путей, болезненной и мягкой при пальпации матки.

Развивающаяся беременность у женщин на сроке от 6 недель 1 день и далее, подтверждалась по результатам УЗИ м/таза (наличие сердцебиения у плода). А у женщин от 4 недель 1 день до 5 недель 6 дней, прогрессирующую беременность устанавливали по нарастанию уровня ХГЧ в динамике.

На момент поступление в стационар у 80 (58\%) женщин был диагностирован инфицированный выкидыш, хотя раннее у них была подтверждённая прогрессирующая беременность, и только у 58 (42\%) пациенток сохранялась прогрессирующая беременность. У 7 (5,1\%) беременность прервалась спустя 3-4 дня после госпитализации, у них было выявлено наличие лейкоцитоза в крови (свыше $10 \times 10^{9} /$ л), но без развития клинической симптоматики инфицированного выкидыша. Клинические признаки развития данной патологии наблюдалось у 51 (36,9\%) пациенток через 5-7 дней с момента госпитализации, помимо лейкоцитоза в крови (свыше 12×109/л), у них наблюдались все признаки инфицирования плода.

Критерии включения в исследования: возраст от 20 до 40 лет включительно в момент госпитализации; инфицированный выкидыш.

Критерии исключения из исследования: возраст пациентки младше 20 лет; старше 40 лет; ВИЧ-позитивные пациентки или пациенты с высоким риском инфицирования, профилактически получающие антиретровирусную терапию; вирусный гепатит В, С, в том числе в анамнезе; криминальное вмешательство; неразвивающаяся беременность. 


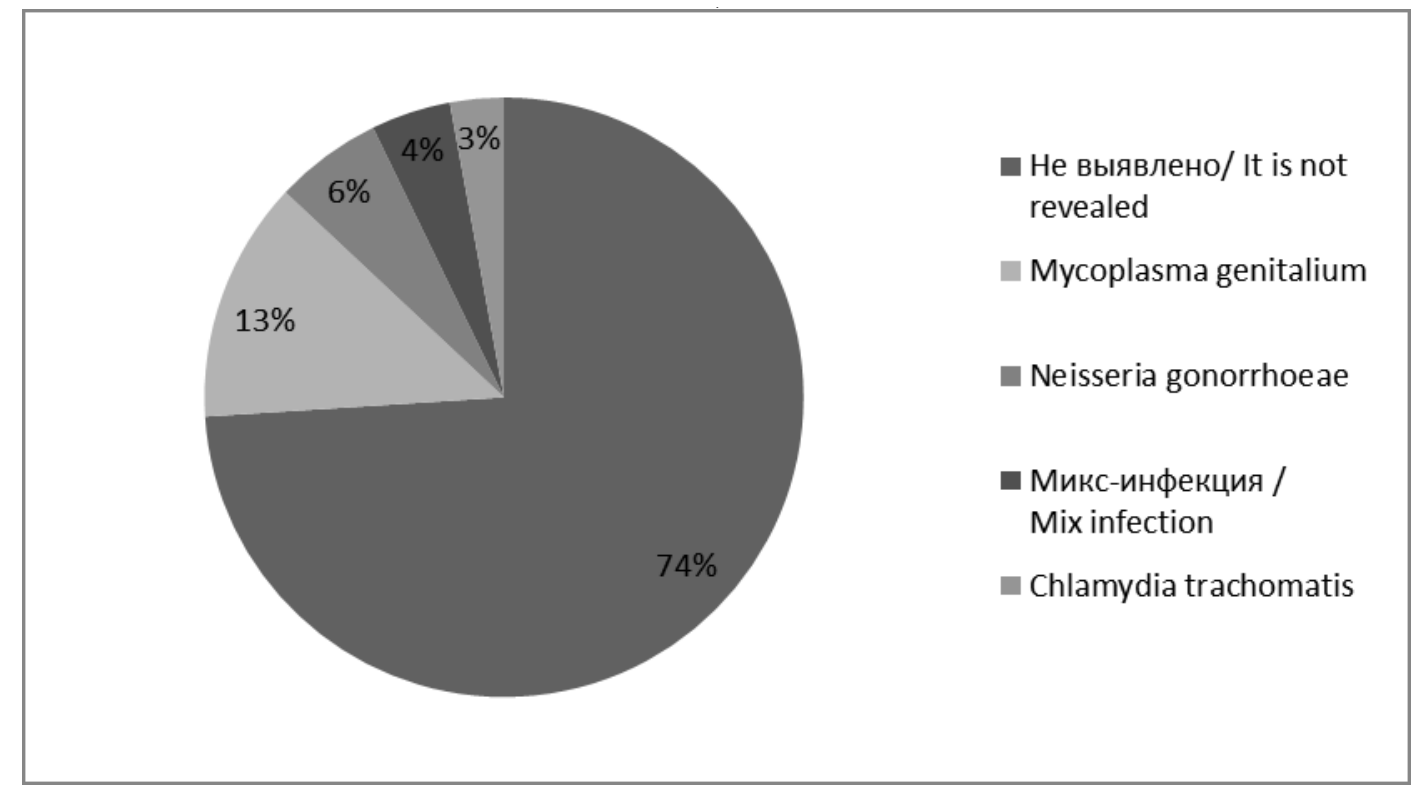

Рис. 1. Содержание патогенных микроорганизмов в урогенитальном тракте у женщин с инфицированным выкидышем при ПЦР исследовании в режиме реального времени

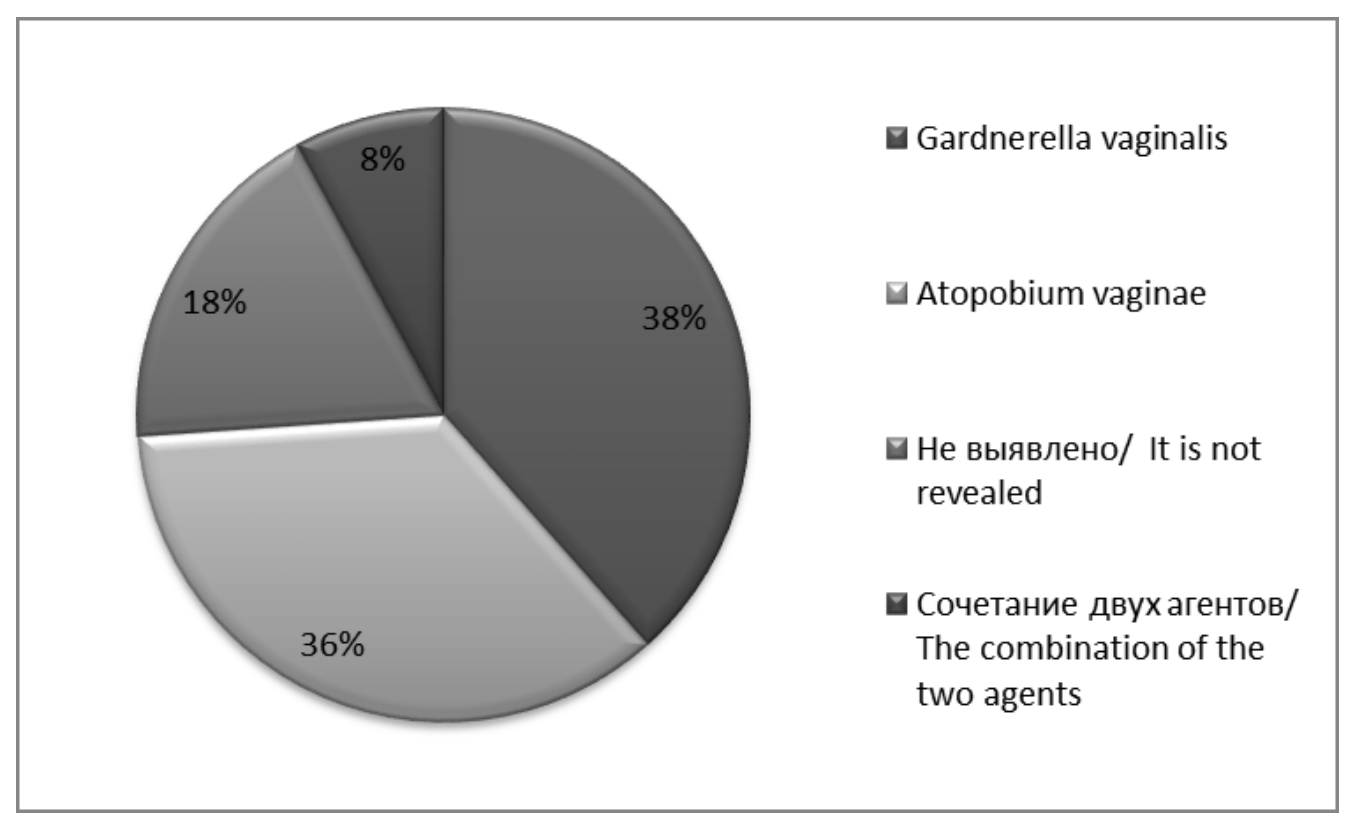

Рис. 2. Содержание строгих анаэробов во влагалище при исследовании методом «Фемофлор 16» у женщин с инфицированным выкидышем

Всем пациенткам выполнялось дополнительно исследование содержимого цервикального канала на репродуктивно значимые инфекции, для этого использовали метод ПЦР в режиме реального времени (ДНК - технология, Москва) для выявления ДНК Chlamydia trachomatis, Mycoplasma genitalium, Neisseria gonorrhoeae, а также тест «Фемофлор-16» для выявления ДНК факультативных и облигатных анаэробов, в том чис- ле Gardnerella vaginalis, Atopobium vaginae, Ureaplasma spp. (urealyticum и parvum), Mycoplasma hominis и др.

Исследование выполнено в соответствии с принципами Хельсинкой декларации Всемирной ассоциации «Этические принципы научных и медицинских исследований с участием человека» и «Правилами клинической практики в Российской Федерации», утвержденным 
Таблица 1. Сравнение частота встречаемости микроорганизмов во влагалищной микрофлоре у женщин с инфицированным выкидышем по данным отечественной и зарубежной литературы и по результатам исследования.

\begin{tabular}{|c|c|c|}
\hline $\begin{array}{l}\text { Микроорганизмы во влагалищной } \\
\text { микрофлоре у женщин } \\
\text { с инфицированным выкидышем/ }\end{array}$ & $\begin{array}{l}\text { Частота встречаемости } \\
\text { микроорганизмов во влагалищной } \\
\text { микрофлоре у женщин } \\
\text { с инфицированным выкидышем } \\
\text { в данном исследовании в\%/ }\end{array}$ & $\begin{array}{l}\text { Частота встречаемости } \\
\text { микроорганизмов во влагалищной } \\
\text { микрофлоре у женщин } \\
\text { с инфицированным выкидышем } \\
\text { в\% по данным отечественной } \\
\text { и зарубежной литературы }[1,9,13,15,16]\end{array}$ \\
\hline \multicolumn{3}{|c|}{ Условно-патогенные микроорганизмы во влагалищной микрофлоре у женщин с инфицированным выкидышем } \\
\hline \multicolumn{3}{|c|}{ Строгие анаэробые микроорганизмы во влагалищной микрофлоре у женщин с инфицированным выкидышем } \\
\hline Gardnerella vaginalis & $38 \%$ & $13,8 \% / 12-60 \%$ \\
\hline Atopobium vaginae & $36 \%$ & $-/ 11-70 \%$ \\
\hline \multicolumn{3}{|c|}{ Факультативные анаэробые микроорганизмы во влагалищной микрофлоре у женщин с инфицированным выкидышем } \\
\hline Enterobacteriacea. & $28 \%$ & $18,9 \%$ \\
\hline Streptococcus spp. & $24 \%$ & $12,7 \% / 56-87 \%$ \\
\hline Staphylococcus spp. & $25,7 \%$ & $18,5 \% / 16-38 \%$ \\
\hline Mycoplasma hominis & $13,8 \%$ & $3,6 \% / 2-12 \%$ \\
\hline Ureaplasma species & $16,7 \%$ & $9,3 \% / 2-15 \%$ \\
\hline $\begin{array}{l}\text { Ассоциация M. Hominis и U.species/ } \\
\text { Association of M. Hominis and U. species }\end{array}$ & $5,8 \%$ & $3,8 \%$ \\
\hline \multicolumn{3}{|c|}{ Патогенные микроорганизмы во влагалищной микрофлоре у женщин с инфицированным выкидышем } \\
\hline Mycoplasma genitalium & $13,0 \%$ & $4,2-7,2 \%$ \\
\hline Neisseria gonorrhoeae & $5,8 \%$ & $1,8-4.4 \%$ \\
\hline Chlamydia trachomatis & $2,9 \%$ & $5.2-5,8 \%$ \\
\hline $\begin{array}{l}\text { Микс-инфекция/ } \\
\text { Mix infection }\end{array}$ & $4,3 \%$ & $39,22 \%$ \\
\hline
\end{tabular}



Рис. 3. Содержание факультативных и/или облигатных анаэробов в значительном титре (> 105 $\mathrm{KOE})$ во влагалище у женщин с инфицированным выкидышем 
Приказом Минздрава РФ № 266 от 19.06.2003, было одобрено локальным этическим комитетом.

\section{Результаты и обсужление}

Наиболее распространённым клиническим проявлением инфицированного выкидыша было развитие эндометрита у 88 (63,8\%), метроэндометрит диагностировали у $38(27,5 \%)$, сепсис у $5(3,6 \%)$ и только у $7(5,1 \%)$ не было клинической симптоматики. Диагнозы устанавливали по наличию характерной симптоматики, по результатам УЗИ м/таза и анализов крови (лейкоцитоз, С-реактивный белок, прокальциотонин).

При анализе результатов обследования (ПЦР в режиме реального времени) абсолютные патогены выявлены у $36(26,1 \%)$ пациенток, что более наглядно представлено на рисунке 1.

При молекулярно-биологическом исследовании отделяемого из влагалища методом «Фемофлор 16» были обнаружены строгие анаэробы (Gardnerella vaginalis, Atopobium vaginae), что представлено на рисунке 2.

В целом, содержание одного или нескольких факультативных (семейство Enterobacteriacea, Streptococcus spp. ( $\beta$-стрептококки групп A, B, C, D, F, G.), Staphylococcus spp. (epidermidis, aureus)) и/или облигатных анаэробов (Gardnerella vaginalis, Atopobium vaginae) в значительном титре (> 105 KOE) продемонстрировано на рисунке 3.

Mycoplasma hominis и Ureaplasma species идентифицировались в 19 (13,8\%) и 23 (16,7\%) пробах, причем сочетание инфектов определялось в 8 (5,8\%) случаях.

Полученные результаты были сопоставлены с данными предыдущих исследований, что более наглядно представлено на таблице 1. В результате сравнения видно, что наблюдается тенденция увеличения частоты неспецифических микробных агентов. При этом наблюдается снижение распространения Chlamydia trachomatis (2,9\%) и микс-инфицкии (4,3\%) (Chlamydia trachomatis, Neisseria gonorrhoeae и Mycoplasma genitalium). Но частота встречаемости Neisseria gonorrhoeae $(5,8 \%)$ и Mycoplasma genitalium (13,0\%) остается на том же уровне.

В ходе исследования установлено, что основными причинами развития воспалительного процесса уро- генитального тракта у женщин с инфицированным выкидышем являются инфицирование абсолютным патогеном и/или активизация условно-патогенной микробиоты влагалища.

Данные факты объясняются микробиологами с позиции общей тенденции к снижению распространенности сексуально - трансмиссивных инфекций. Также нерациональное применение антибактериальных препаратов и эволюция микробиоты способствует формированию устойчивых штаммов и активному обмену генетическим материалом в полимикробных ассоциациях, вследствие чего условно - патогенная микробиота может приобретать патогенные свойства. Верификация микробиоты урогенитального тракта позволяет применить дифференцированный подход к назначению антибактериальной терапии, особенно при необходимости продолжения лечения.

Учитывая полученные данные необходимо рекомендовать определение качественного и количественного состава микробиоты урогенитального тракта, которые должны выполняться до начала лечения, что позволит произвести адекватную смену противомикробной терапии в случае ее неэффективности.

Адекватная противомикробная терапия является главным компонентом комплексного лечения, при этом всегда следует предполагать участие грамотрицательных, грамположительных анаэробов и аэробов, гонококков и хламидий, а также возможную резистентность микроорганизмов к традиционным препаратам эмпирической терапии.

\section{Bывод}

При сравнении результатов исследования качественного и количественного состава микробиоты урогенитального тракта у женщин с инфицированным выкидышем с данными последних пяти лет, выявлено увеличение количества условно-патогенной флоры (Gardnerella vaginalis, Atopobium vaginae Streptococcus spp., Staphylococcus spp. и др.), увеличение сочетания Mycoplasma hominis и Ureaplasma species (5,8\%), при одновременном снижении частоты выявления возбудителей ИППП (Chlamydia trachomatis) или сочетание инфекций ассоциированных с ИППП (Chlamydia trachomatis, Neisseria gonorrhoeaе и Mycoplasma genitalium).

\section{ЛИТЕРАТУРА}

1. Евстигнеева Н.П., Аминева П. Г., Герасимова Н. А. Возможности инновационного массспектрометрического метода в определении этиологически значимой микробиоты урогенитального тракта пациенток репродуктивного возраста. Международный журнал прикладных и фундаментальных исследований № 6, 2016 С. 682-686. 
2. Кузьмин В.Н., Гусейнзаде М. И. Современные представления о роли микоплазменной инфекции в структуре воспалительных заболеваний органов малого таза. Cons. Med. Женское здоровье (Прил.). 2011; 13 (6): С. 40-45.

3. Лысяк Д.С., Путинцева 0. Г., Быстрицкая Т.С. Самопроизвольный аборт: учебное пособие - Благовещенск: 2014, С. 95

4. Письмо Минздрава России от 7 июня 2016 г. N15-4/10/2-3482. Клинические рекомендации (протокол лечения) «Выкидыш в ранние сроки беременности: диагностика и тактика ведения», С. 32.

5. Савичева А.М., Соколовский Е. В., Тапильская Н. И. и др. Инфекционно-воспалительные заболевания в акушерстве и гинекологии. Руководство для врачей/ Под редакцией Э. К. Айламазяна. Москва, 2016., С. 314.

6. Тапильская Н.И., Савичева А., Шипицына Е. В. Применение препарата Лактоженаль для коррекции нарушений микробиоценоза влагалища у беременной с наложенным швом на шейку матки: клинический случай и обзор литературы. Журнал акушерства и женских болезней 2016, 65(6): С. 89-95.

7. Татарова Н. А. Клинико-морфологические аспекты вынашивания и невынашивания беременности: дис. д-ра мед. наук. - СПб., 2010.— С. 345.

8. Филиппов 0.С., Гусева Е. В., Сидорова И. С., Никитина Н. А. Материнская смертность в Российской Федерации: анализ официальных данных и результаты конфиденциального аудита в 2013 году. Методическое письмо Министерства здравоохранения Российской Федерации № 15-4/10/2-7509 0т 02.10.2014; C. 91.

9. Хурасева А.Б.,. Реминная Т. В. Нарушения микробиоценоза вагинальной среды у женщин репродуктивного возраста и возможности его коррекции. Региональный вестник № 17 (32), 2019 С. 3-7.

10. Цечоева Л.Ш., Тапильская Н. И. Ассоциация генетических полиморфизмов с инфицированным выкидышем. Мультидисциплинарные аспекты молекулярной медицины. Издательство Санкт-Петербургского Государственного Экономического Университета. 2017; С. 84-86.

11. Шаршова 0.А., Быстрицкая Т. С., Жуковец И. В. Септические осложнения абортов: учебное пособие — Благовещенск: 2014, С. 109.

12. Barrons R et al. Use of Lactobacillus probiotics for bacterial genitourinary infections in women: a review. Clin. Ther 2008; 30 (3): $453-68$.

13. Campos, G. Prevalence of Mycoplasma genitalium and Mycoplasma hominis in urogenital tract of Brazilian women / G. Campos, T. Lobao, N. Selis [et al.] // BMC Infect. Dis. - 2015. - Vol.15. - P. 2-8.

14. Elias M et al. The presence of Mycoplasma hominis and Ureaplasma urealyticum in the cervical canal of uterus. Ginekol Pol $2005 ; 76$ (1): $28-32$.

15. Gesink, D. C. Mycoplasma genitalium in Toronto, Ont: estimates of prevalence and macrolide resistance / D. C. Gesink, C. S. Racey, C. Seah // Can. Fam. Physician. 2016. — Vol.62.— № 2.—P. 96-101.

16. Gomih-Alakija, A. Clinical characteristics associated with Mycoplasma genitalium among female sex workers in Nairobi, Kenya / A. Gomih-Alakija, J. Ting, N. [et al.] // Mugo Journal of Clinical Microbiology.— 2014.— Vol. 52.— № 10.— P. 3660-3666.

17. Taylor-Robinson D et al. Futher observations on the murine model of Mycoplasma hominis infection. J Med Microbiol 2010; 59 (8): $970-975$.

() Рухляда Николай Николаевич, Винникова Симона Викторовна ( simona.vinnikova@yandex.ru ),

$$
\text { Цечоева Лейла Шахмурзаевна. }
$$

Журнал «Современная наука: актуальные проблемы теории и практики» 